\title{
Learning Techniques among Adult Students in Higher Learning Institutions, Ministry of Higher Education Malaysia
}

\author{
Ashari bin Sikor \\ Faculty of Technical Education \\ Universiti Tun Hussein Onn Malaysia, Malaysia \\ E-mail: ashari@uthm.edu.my \\ Sapon bin Ibrahim \\ Faculty of Technical Education \\ Universiti Tun Hussein Onn Malaysia, Malaysia \\ E-mail: sapon@uthm.edu.my
}

Mohamad Hisyam bin Mohd. Hashim

Faculty of Technical Education

Universiti Tun Hussein Onn Malaysia, Malaysia

E-mail: mhisyam@uthm.edu.my

Ahmad Rizal bin Madar

Faculty of Technical Education

Universiti Tun Hussein Onn Malaysia, Malaysia

E-mail: rizalm@uthm.edu.my

Received: July 12, 2012 Accepted: October 30, 2012 Published: Nowember 1, 2012

doi:10.5296/jse.v2i4.2097ＵRL: http://dx.doi.org/10.5296/jse.v2i4.2097 


\section{Abstract}

A suitable learning technique among adult students especially in the early adult age.

could create an active and conducive learning environment. The objective of this study is to investigate the problems faced by students during learning process. The study also will identify the dominant learning technique being practiced by most of the students. In addition, the study will also point out the most suitable learning technique for the present time adult students. Apart from that, the study will also identify if there is a relationship between students' learning technique with their demographical aspects. This study focused on students in the early adult age that is students who are undergo the course of Bachelor of Education (Technique and Vocational) at UTHM. They are in the age of 21 years old and above. Sample of the research involved 108 students. The research is carried out qualitatively through the instruments of survey forms and supporting interviews. All data obtained are analyzed by using the Statistical Package for Social Science (SPSS) software version 12.0 in order to find the min score, percentage and standard deviation. Spearman's Rho correlation is used to attain the relationship between student's learning technique with their demographical aspects namely, their gender, race, age and academic achievement. The findings of the research show that the common problem usually faced by students is being too worried about the academic achievement. Where as, the dominant learning technique used by adult students are discussion and memorizing techniques. Furthermore, there is a slight relationship between students' learning technique with their age. Consequently, it is highly hoped that this research could benefit all the entities involved. There are also some suggestions stated in this research for the purpose of improving the learning techniques of students.

Keyword: Learning Techniques, Adult Students, Higher Learning Institutions 


\section{Introduction}

The world of education has expanded significantly with changes involving aspects of philosophy, system change, curriculum change, vision and mission change as well as in terms of pedagogical aspect in line with the current requirements (Rusli Mahmood, 2002). In order to cope with this challenge, higher learning institutions should be capable of producing excellent world class teachers. Driven by this necessity, the Teacher Training Division of the Malaysia Ministry of Education has embarked on more systematic training courses in line with the requirement of teachers based on subjects in school (Lokman A. Wahid et. al., 2003).

Teaching is a process where selection (overt selection) and arrangement of information, activity, approach and medium to assist students identifying the objective of learning. The selection of teaching strategy and suitable teaching aids to teach certain selected topic. Activities that will be carried out during teaching process also need to be identified to assure that the process will run smoothly and effectively. In other words, teaching is a dynamic process that depends on the condition of the students, the environment of the learning process as well as the topic to be taught.

Adult student definition involved the whole planned education process for adults. This is because the aim of adults' education is broad involving their determination to develop skills, enriching knowledge as well as improving their qualification and professionalism. Therefore, the approach of teaching carried out should be suitable since in adults' education phase, the facilitator need to be more sensitive towards the differences of adult students' principals compared to the pedagogy. For example, the facilitator needs to take into account the factor of students' experiences because andragogy is different from pedagogy which is more towards the child's psychological education. In this perspective, the Teaching and Learning Model introduced by Knowles based on his assumption would be an alternative to assist in an effective teaching and learning process.

In the Europe and the United Stated, Adult's education is a social requirement that goes along with the formation of democracy and industrial revolution. Adult's education happened for the first time in Europe in England during the early of nineteenth century. Whereas it only occur in the United States of America at the end of the nineteenth century as an additional subject for the adults in universities, public libraries and museums (Gesner, 2000).

Mohd Azhar et. al. (2004) stated that, adults' education is a mark of movement in changing the community towards a meaningful life and it is also a strategic movement in the new life of American community in the old days. He therefore stated that, this lifelong learning is a heritage of the ancestors' of American and European community. Thus, the development of human being can be performed if attention is paid to adults' education since this learning process needs to be quickly expands in line with the development of the country.

In the methodology of Adults' Education, practically the instructions for the adults need to be focused more on the process compared to the content. Strategies such as case study, simulation and self assessment are the most effective. Teachers' role is more as facilitators and less as lecturer or assessor. Thus, it can be seen that, adults learning process is a technique in teaching 
and learning method where it involves the process where adult students reallize how to evaluate experiences obtained to solve problems. According to Esah Sulaiman (2004), it is clear as stated by Knowles (1968) in the principals of adult students.

\section{Background of Problems}

In general, the education system can be said as consisting of two main roles. First role is as a machine to provide trained manpower in varieties of knowledge and skills to boost the country's economic growth. Whereas on the other hand, students are hoped to be equally balanced in terms of emotional, spiritual, physical an intellectual through the formal education system. Thus, education institutions are where the process of education occurs to prepare students for the workplace requirement. It is clear that education institutions have a vital role. For instance, schools are said to be able to play the role effectively as well as evaluating the progress of students in the precise manner.

Before entering the workplace, a complete preparation consists of varieties of aspects especially in terms of knowledge is paramount. According to Mok Soon Sang (2002) learning is a process of gaining knowledge or skills and it is occurs through trainingsi or experiences that will be able to change the behavior of a human permanently and consistently. By practicing the experiences and knowledge obtained from the learning process, it can be considered as change in human's behavior. As agreed by Honey and Mumford (1992), learning took place when human can show or do something new, although in the form of comprehension, realization or capability of doing certain skills. There is certain eagerness shown or possessed by individual in the process of learning. There are eagerness to gain experience when learning something, eagerness to recalling something, eagerness to draw conclusion and eagerness to implement. Learning process also need to be seen as a qualitative change when an individual is seeing, experiencing and embracing something in the real world.

In The 9th Malaysia Plan, The Prime Minister Datuk Sri Abdullah Ahmad Badawi stressed on the need of the country to have first class human capital. This statement has been an issue nationally especially in the field of education. It is also has been a challenge to the Ministry of Higher Education. In conjunction, Higher Learning Institutions in the country are being obligated to produce graduates with skills and character so that they can compete globally. Nevertheless, few evidences show that the desired graduates are still short on production due to their lack of suitable learning technique especially among adult students (Mohd Najib, 2005).

Amran (2004) found out that, most of students depend only to the lecturer in getting knowledge. He also stated that, learning process of adult students only concentrated in the class and they never do any revisions at home. Based on this, it might have been caused by factors such as fatigue, interruption from children, husband or wife. Excellent achievement in academic is not only depends on effective learning technique. The usage of study method or technique is also important in order to success. This is concerning especially to adult students who have many kind of problems such as financial problem, personal problems and problems to allocate spare time to study. Thus, adult students should be smart enough to use the right study technique so that they can blend into the learning process effectively and systematically (Sharuddin, 2005). 
Whereas, according to Abu Bakar et. al. (1997), factors of financial, family and time management are the main limitation in their learning process. This is because financial condition and time allocation are the important aspects for student who are married and have family pursuing their studies in universities. Student nowadays are more exposed to social activities and advances of technologies so quality time of study and ideal study environment are quite limited for them.

Decline in students' academic performance is something that cannot be neglected especially when involving students in higher learning institutions. If this problem is not controlled during the early stage, image of a certain university or institution will be affected badly in the eyes of the community. This could leads to loss of trust from the community and they will no longer sending their children to that particular university or institution. In the process of gaining excellent academic achievement a student must have desire and aim to be successful. There are some elements that could disturb success. Elements that could disturb success are not having clear objectives, no ambitions, incapable to manage time correctly, lazy, lack of spirits and think negatively (Sulaiman, 2002).

If learning technique especially for adult students can be identified and complete with proper guidance, failure to achieve excellent academic performances could well be avoided. This is because students that know for themselves their learning technique can learn about certain subject better. They will be able to understand the concept clearly. Hence, academic success among adult students are highly depends on the learning technique practiced by them.

\section{Statement of Problem}

The world of education has been expanding extensively involving the aspect of philosophy, system changes, curriculum changes, mission and vision changes as well as changes in pedagogical approaches so that it could suite the current requirement (Rusli Mahmood, 5002: 54). Lecturers teach in any local institutions such as Public or Private or even Poly Technique Colleges are highly qualified for the job. There are few findings in the field of human resource show that most of students are unable to use suitable learning technique especially among the adult students who are doing part time studies. This statement goes along with Anderson et. Al. (1949) saying that, most students are highly depending on the teacher or lecturer for the knowledge. Moreover, the most practiced learning technique is group discussion and listening. Apart from that, Adult learning process only concentrated in the class and they do not do any revision at home due to some factors such as fatigue, lack of time and etc. Based on this statement, a research has been carried out to identify problems from the aspects of learning among adult students in the Public Higher learning Institutions, Ministry of Higher Education Malaysia.

\section{Research Objective and Questions}

To investigate the problems faced during learning process among adult students in pursue of improving their academic achievements. To determine the dominant learning technique practiced and to identify the relationship between learning technique and students' demographical aspects. The Research questions are what are the learning problems faced by 
adult students in the chase of improving their academic achievement?, what is the dominant learning technique practiced by adult students?, what is the most suitable technique in the context of adult students learning nowadays?

Is there a significant relationship exist between students learning technique and their demography?

\section{Scope of Study}

The study focuses on the problems faced during learning process among adult students of Education Faculty in Public Higher Learning Institutions. Besides that, this research also focuses on the dominant learning technique practiced. Furthermore, the most suitable technique for adult student in current time is also focused. Finally, this research also identified the relationship between learning technique and students' demography. In this research, researcher limits the study only on certain aspects so that the scope will not be too broad. According to Mohd Najib (2003), a researcher will not be able to study all aspects of the problem being analyzed. This research only involved a public institution of higher learning namely the UTHM which offers the Technique and Vocational Education Program. This research is specially carried out to identify learning techniques suitable for adult students who are undergoing master degree course. It is predicted that the findings would be able to contribute on improving the effectiveness of academic programs among adult students in Public Institution of Higher Learning, Ministry of Higher Education. This research also will offer some suggestions for the teaching staffs so they can overcome problems faced by adult students in higher learning institutions.

\section{Research Methodology}

\section{Design of Research}

This research is carried out qualitatively. Methods of survey forms and interview to support data obtained from the survey forms. The objective of the research is to identify problems faced by adult student in their learning process when they desire a successful achievement academically. Besides that, this study also aims to find the current dominant learning technique practiced by adult students who are undertaking Master program in UTHM. The techniques being studied are reading technique, remembering or memorizing, mind map note taking, individual learning and group discussion technique. Location of research is in the Universiti Tun Hussein Onn Malaysia (UTHM), concentrating on students of Master of Education in Technique and Vocational. Group sampling is taken from students of Master of Education in Technique and Vocational in UTHM. This group of student is chosen based on their existing fundamentals on pedagogy subject, possessing working experience, basic biology, law, psychology and social. They are also in the early adult age. Instruments used in this research are a survey form and an interview. The survey form consists of four parts namely Part A, Part B, Part C, and Part D. Every question is close ended type so that they would be easier to be answered since the respondents are students. Part $\mathrm{B}$ and Part $\mathrm{C}$ contained 8 items pertaining to the problems encountered during learning process and concerning learning technique. 
A preliminary study has been carried out on 30 students to determine the reliability of the items in the survey form. Data obtained from this preliminary study are being anallyzed and any items found to be not reliable were enhanced. The preliminary outcome shows that the reliability of the survey form is a value of Alpha Cronbach 0.909. According to Mohd Najib Abdul Ghafar (1999), High reliability of a certain instrument has a value of Alpha Cronbach more than 0.80 . The data was carried out based on items in every part of the survey form. All data were accumulated and processed using SPSS version 12.0 for Windows. Outcomes of the data analysis are then being presented in tables form. Data obtained were analyzed in inference way as well as descriptive by performing min score calculation to answer every research question.

\section{Research Findings}

Table 1 shows the analysis of personal information of respondents. 71 (66\%) of the respondents are female students whereas 37 (34\%) are male students. Besides that, analysis shows that, Malay respondents are the most recorded which is 91 (84\%) follows by other race of 7 (6\%), 5 Chinese (5\%) and 5 Indian (5\%). There are 67 students (62\%) aged 21 to 25 years, 40 students (37\%) aged 26 to 30 years, and only 1 student (1\%) aged more than 30 years old. In terms of academic achievement, There are 3 (3\%) students with results of 2.30 2.99, 77 students (71\%) with results of 3.00 3.69 and 28 students (26\%) with results of 3.70 4.00.

Table 1. Personal Information Analysis of Respondents

\begin{tabular}{|c|c|c|c|}
\hline No. & Respondents Description & Number of Students & Percentage (\%) \\
\hline \multirow[t]{3}{*}{1.} & Gender: & & \\
\hline & Male & 37 & 34 \\
\hline & Female & 71 & 66 \\
\hline \multirow[t]{5}{*}{2.} & Race: & & \\
\hline & Malay & 91 & 84 \\
\hline & Chinese & 5 & 5 \\
\hline & Indian & 5 & 5 \\
\hline & Others & 7 & 6 \\
\hline \multirow[t]{5}{*}{3.} & Age: & & \\
\hline & 20 years and below & 0 & 0 \\
\hline & 21-25 years & 67 & 62 \\
\hline & 26-30 years & 40 & 37 \\
\hline & 30 years and above & 1 & 1 \\
\hline \multirow[t]{6}{*}{4.} & Academic Achievement: & & \\
\hline & 2.00 and below & 0 & 0 \\
\hline & 2.00-2.29 & 0 & 0 \\
\hline & $2.30-2.99$ & 3 & 3 \\
\hline & $3.00-3.69$ & 77 & 71 \\
\hline & $3.70-4.00$ & 28 & 26 \\
\hline
\end{tabular}




\section{Problems during Learning Process}

Table 2. Min Score Item of Problems during Learning Process

\begin{tabular}{llllll}
\hline Variables & & $\begin{array}{l}\text { Item No. } \\
\text { I }\end{array}$ & $\begin{array}{l}\text { Number of } \\
\text { Item }\end{array}$ & $\begin{array}{l}\text { Overall } \\
\text { Min }\end{array}$ & Level \\
\hline $\begin{array}{l}\text { Problems } \\
\text { Process }\end{array}$ & during & Learning & $5-12$ & 8 & 2.84 \\
\hline
\end{tabular}

Min Score Range : 1.00-2.00 (low), 2.01-3.00 (Medium), 3.01-4.00 (High)

Table 2 shows the Overall Min Score of Item of Problems during Learning Process. Base on the table, the overall min value is 2.84 which in medium level. The result show that a lot of adult students of Master in Technique and Vocational Education are likely tend to worry about their academic achievement compared to other problems. Thus, it can be concluded that, the stated item is the problem that frequently faced by student whether in university level or even school level.

\section{Dominant Learning Technique Practiced}

Table 3. Analysis Variable of Items on Learning Technique, $N=108$, Likert Scale 1-4

\begin{tabular}{lllll}
\hline Variables (Learning Technique) & Item No. & $\begin{array}{l}\text { Number of } \\
\text { Item }\end{array}$ & Min & Level \\
\hline Reading & $13-20$ & 8 & 3.14 & High \\
Remembering/ Memorizing & $21-28$ & 8 & 3.37 & High \\
Mind Mapping Notes & $29-36$ & 8 & 3.13 & High \\
Individual Learning & $37-44$ & 8 & 2.86 & Medium \\
Group/ Discussion & $45-52$ & 8 & 3.27 & High \\
Total & $13-52$ & 40 & 3.15 & High \\
\hline
\end{tabular}

Min Score Range: 1.00-2.00 (low), 2.01-3.00 (Medium), 3.01-4.00 (High)

Based on data in Table 3, results show that the dominant learning techniques practiced by students are Remembering and Group/Discussion with min of 3.37and 3.27 respectively. Reading and Mind Mapping techniques with min value of 3.14 and 3.13 respectively. Whereas Individual Learning also moderately being practiced with min value of 2.86 .

\section{Suitable Learning Technique with Current Learning Concept}




\section{Macrothink}

Table 4. Frequency and Percentage of Popular Learning Techniques Nowadays

\begin{tabular}{lll}
\hline Learning Technique & Number of Respondents & Percentage (\%) \\
\hline Reading & 3 & 2.8 \\
Remembering & 6 & 5.5 \\
Mind Mapping Notes & 25 & 23.1 \\
Individual Learning & 10 & 9.3 \\
Group/ Discussion & 64 & 59.3 \\
Total & 108 & 100 \\
\hline
\end{tabular}

Table 4 shows that, the most suitable Learning technique is Group/ Discussion which recorded percentage of $59.3 \%$ follows by $23.1 \%$ practicing Mind Mapping Notes as their learning technique. Furthermore, 9.3\% chose to learn individually and 5.5\% like to use Remembering/ Memorizing technique as their alternative. On the whole, it shows that adult students in Master of Technique and Vocational Education Course chosen Group/ discussion technique as their current concept of learning.

\section{Relationship between Learning Technique and Gender}

Table 5. Relationship between Learning Technique and Students’ Gender

\begin{tabular}{llll}
\hline & & Gender \\
\hline Spearman's & \multirow{2}{*}{ Learning Technique } & Correlation Coefficient & 0.054 \\
Rho & Sig. (2-tailed) & 0.576 \\
\hline
\end{tabular}

$\mathrm{N}-$ No. of Respondents $=108$

Table 5 shows the data from analysis carried out using the method of Spearman's Rho Correlation. Based on the finding, there is a weak value of positive correlation with values of $r$ $=0.054, p=0.576$ where $p>0.05$. Therefore HO1 can be accepted where there is no significant relationship statistically between learning technique and students' gender.

\section{Relationship between Learning Technique and Race}

Table 6. Relationship between Learning Technique and Students’ Race

\begin{tabular}{llll}
\hline & & Race \\
\hline Spearman's & \multirow{2}{*}{ Learning Technique } & Correlation Coefficient & -0.121 \\
\cline { 3 - 4 } & & Sig. (2-tailed) & $0.2 \mathbb{1 3}$ \\
\hline
\end{tabular}

$\mathrm{N}-$ No. of Respondents $=108$ 


\section{Macrothink}

Table 6 shows the data from analysis carried out using the method of Spearman's Rho Correlation. Based on the finding, there is a weak value of negative correlation with values of $r$ $=-0.121, \mathrm{p}=0.213$ where $\mathrm{p}>0.05$. Therefore HO2 can be accepted where there is no significant relationship statistically between learning technique and students' race.

\section{Relationship between Learning Technique and Age}

Table 7. Relationship between Learning Technique and Students’ Age

\begin{tabular}{llll}
\hline & & Age \\
\hline Spearman's & \multirow{2}{*}{ Learning Technique } & Correlation Coefficient & 0.234 \\
Rho & Sig. (2-tailed) & 0.015 \\
\hline
\end{tabular}

$\mathrm{N}-$ No. Of Respondents $=108$

Table 7 shows the data from analysis carried out using the method of Spearman's Rho Correlation. Based on the finding, there is a weak value of positive correlation with values of $r$ $=0.234, \mathrm{p}=0.015$ where $\mathrm{p}<0.05$. Therefore HO3 is unacceptable where there is a significant relationship statistically between learning technique and students’ age.

\section{Relationship between Learning Technique and Academic Achievement}

Table 8. Relationship between Learning Technique and Students’ Academic Achievement

\begin{tabular}{llll}
\hline & & Academic Achievement \\
\hline Spearman's & \multirow{2}{*}{ Learning Technique } & Correlation Coefficient & 0.01 \\
Rho & & Sig. (2-tailed) & 0.937 \\
\hline
\end{tabular}

$\mathrm{N}-$ No. of Respondents $=108$

Table 8 shows the data from analysis carried out using the method of Spearman's Rho Correlation. Based on the finding, there is a weak value of positive correlation with values of $r$ $=0.01, \mathrm{p}=0.937$ where $\mathrm{p}>0.05$. Therefore HO4 can be accepted where there is no significant relationship statistically between learning technique and students’ academic achievement.

\section{Discussion}

Based on the findings of this research, a lot of adult students doing the course of Master of Education in Technique and Vocational tend to reveal that the most common problem they faced is worrying about their academic achievement. This shows that the problem is commonly experienced by students in university level and also in school level. Having too worried about their academic achievement is might be due to their study or learning technique. Most of the students are not smart enough to pick the suitable technique for themselves. This phenomenon 
also agreed by Abdul Ghani (1996) that states, one of the causes of decline in students' academic achievement is due to their failure in adapting to the teaching and learning style in University. They also do not have the correct and suitable learning style. Consequently, a lot of them failed to obtain excellent results and admitted that they are lacking of knowledge in learning skills. They failed to search for the most suitable learning technique to suite their attitude.

On the whole, the dominant learning techniques among students in the course of Master of Education in Technique and Vocational is Remembering / Memorizing technique, follows by Group/ Discussion, Reading and Note Making. Whereas, Individual learning technique also in fairly moderate practices. The practiced learning techniques have to be suitable with the condition of being the students enrolled in Master of Education in Technique and Vocational due to the importance of adapting with individual differences. Thus, it is clear that every student needs to have their own technique of studying. This is also agreed by Hassan (1996) where he states that a lot of students with the right learning technique are doing well in the examinations. Nevertheless, this finding opposes the finding of Robiah (2004) who says that remembering technique is not the dominant technique used by students. Moreover, remembering technique also not popular among early adult and adult students.

Nowadays, Group or Discussion learning technique is a suitable and preferred way of studying for early adult aged students. This technique fitting well with the condition of students where at early adult age, they like to discuss in groups compared to other techniques of learning. Discussion or Group technique could provide them the chances to interact with others freely. Conducive learning environment will results in happy learning situation experienced by students. Besides that, Group or Discussion learning technique also can create a social context in the process of assignment preparation. According to Johnson and Johnson (2003), when students are studying through Group or discussion method, they could help each other to understand the topic of discussion. They also could perform their ability based on individual potentials.

Based on the findings of this research, there is a significant relationship exist between learning technique and age of students. It can be seen that relationship between technique and age is fairly weak although the value of correlation coefficient is a positive value. Relationship between learning technique and age are according to the five learning techniques which are reading, remembering, mind mapping notes, individual learning and group or discussion technique. Whereas this research found that the other demographical aspects of students namely the gender, race and academic achievement have nothing to do with students' learning techniques. All the findings stated are in line with the statement of Ee Ah Meng (2003) who claimed that learning technique is formed by students since they were child and will keep developing and being utilized by individuals. This means that adult students will tend to use learning technique that will give them the best outcomes for their academic achievement. Meanwhile, younger students tend to use the beginners approach that has negative correlations towards their academic achievement. This statement also agreed by Kalat (2004) that says students' thinking process changes with their age. Thus as the age individuals increase, their way of thinking and learning technique will change. 


\section{Conclusion}

This research can be carried out successfully because all parties involved were giving full cooperation such as permission given to researcher by lectures as well as permission by students who answered the instruments of the research. Adult students chosen to answer questions of the instruments are assumed to be honest in answering because there was no stressful environment of answering so that they could answer all the questions carefully and precisely.

As planned, this research was carried out to study the problems encountered by students in learning process, the dominant learning technique used and the suitable learning techniques in the learning context nowadays. In addition, the research also identifies the relationship between learning techniques and students' demographical aspects. Outcomes of the study have answered all the research questions set. It is highly expected that this particular research can provide some information and guidance to students, educators, parents and other parties who involved directly or indirectly in putting education as first priority in this country. Cooperation among all parties is highly demanded in order to achieve the desired objective of excellent in the search of knowledge.

\section{References}

Abdul Ghani Awang. (1996). Learning Skills in Higher Learning Institutions. Kuala Lumpur: Dewan Bahasa dan Pustaka.

Abu Bakar Hashim. (et. Al). (1997). Research on Students’ Achiement in Universiti Teknologi Malaysia. Faculty of Education, UTM.

Anderson, I. H. (et.al). (1949). The Psychology of Teaching Reading. New York: Roland Press.

Ee Ah Meng. (1992). Pedagogy, An Introduction. Kuala Lumpur: Fajar Bakti Publication Sdn. Bhd.

Esah Sulaiman. (2004). Introduction to Pedagogy. Johor: Universiti Teknologi Malaysia Publication.

Hassan Ali. (1996). Effectice Learning Strategy. Kuala Lumpur: Publications \& Distribution Sdn. Bhd.

Honey dan Mumford. (1992). The Manual of Learning Styles. Berkshire, 3rd Edition. United Kingdom: Peter Honey.

Johnson, D. W., \& dan Johnson, R. T. (2003). Learning Together and Alone: Cooperative Competition and Individualistic Learning. USA: Prentica Hall.

Kalat, J. W. (2004). Introduction to Psychology. United States: Wadsworth Pub. Co.

Knowles. (1970). Andragogy- Concepts. Downloaded on 5 Mac 2008 from the blog.persimpangan.com/blog/2007/08/15/andragogi-concepts 
Lokman A. Wahid. (et. Al). (2003). Perception of Students on the implementation of Option Subject in Teacher Training College. Kuala Lumpur : Institute of Bahasa Melayu Malaysia.

Mohd Azhar. (et. Al). (2004). Andragogy : Teaching the Adults How to Learn. Improvent In Education Series, PTS Publications \& Distribution Sdn. Bhd.

Mohd Najib Abdul Ghafar. (2003). Education Research. Universiti Teknologi Malaysia Publication.

Mohd Najib Abdul Ghaffar. (et. Al). (2005). Personality Characteristics in teh Selection of Students Carier Path, Style of Learning and their Relationship Towards Academic Achievements. Johor: Universiti Teknologi Malaysia.

Mok Soon Sang. (2002). Teaching Education Series: Pedagogy of Teaching Diploma Semester 3. Subang Jaya: Budiman Groups Sdn. Bhd.

Robiah Zakaria. (2004). Relationship between Students Learning Culture with Academic Achievement in Technical Field. : A Reaserch in Sekolah Menengah Teknik (SMT) Johor. Kolej Universiti Teknologi Tun Hussein Onn: Master Thesis.

Rusli Mahmood. (2002). Technology as the Tool in the Implementation of Smart School and Management of Smart Learning. The Education Journal, 9. Kota Bharu: Kota Bharu Teacher Training College.

Sharuddin A. Latiff. (2005). Full Time Adult Students Learning Techniques in UTM”. National Proceeding Seminar, UTM.

Sulaiman Masri. (2002). Excellent Students. Kuala Lumpur: Publication \& Distribution Sdn. Bhd. 